This is the final peer-reviewed accepted manuscript of:

Dragone, D., Prarolo, G., Vanin, P., \& Zanella, G. (2019). Crime and the legalization of recreational marijuana. Journal of Economic Behavior \& Organization, 159, 488-501.

The final published version is available online at:

http://dx.doi.org/10.1016/j.jebo.2018.02.005

(C) 2019. This manuscript version is made available under the Creative Commons AttributionNonCommercial-NoDerivs (CC $\quad$ BY-NC-ND) $4.0 \quad$ International License http://creativecommons.org/licenses/by-nc-nd/4.0/ 


\title{
Crime and the legalization of recreational marijuana*
}

\author{
Davide Dragone $^{\dagger} \quad$ Giovanni Prarolo ${ }^{\dagger} \quad$ Paolo Vanin $^{\dagger} \quad$ Giulio Zanella ${ }^{\dagger \dagger}$
}

January 29, 2018

\begin{abstract}
First-pass evidence is provided that the legalization of the cannabis market across US states is inducing a crime drop. We exploit the staggered legalization of recreational marijuana enacted by the adjacent states of Washington (end of 2012) and Oregon (end of 2014). Combining county-level difference-in-differences and spatial regression discontinuity designs, we find that the policy caused a significant reduction in rapes and property crimes on the Washington side of the border in 2013-2014 relative to the Oregon side and relative to the pre-legalization years 2010-2012. The legalization also increased consumption of marijuana and reduced consumption of other drugs and both ordinary and binge alcohol. Four possible mechanisms are discussed: the direct psychotropic effects of cannabis; substitution away from violence-inducing substances; reallocation of police effort; reduced role of criminals in the marijuana business.
\end{abstract}

Keywords: cannabis, recreational marijuana, crime

JEL codes: K23, K42

*A previous version of this paper circulated under the title "Recreational cannabis reduces rapes and thefts: Evidence from a quasi-experiment". We are grateful to Sebastian Galiani, Ernesto Schargrodsky, an anonymous referee, as well as seminar participants at the University of Padova, the Social Choice Research Group 2016 meeting in Florence, the America Latina Crime and Policy Network 2017 meeting in Santiago del Chile, and the 2017 Workshop on Inequality, Intergenerational Mobility, and Organized Crime in Trapani for valuable comments and suggestions. All errors are ours.

${ }^{\dagger}$ University of Bologna, Department of Economics. Piazza Scaravilli 2, 40126 Bologna, Italy

${ }_{\ddagger}^{\ddagger}$ Corresponding author. E-mail: giulio.zanella@unibo.it. 


\section{Introduction}

The full legalization of the American cannabis market (production, sale, and consumption) began in 2012 in the states of Colorado and Washington, where the first recreational marijuana laws were passed. By the end of 2017, recreational cannabis is legal in 9 US states (and DC), comprising $22 \%$ of the US population, and more states are likely to follow soon. ${ }^{1}$

This legalization wave is raising concerns about the crime impact of a permissive drug policy. For instance, in October 2016, shortly before voters in California cast their ballot on Proposition 64 (a voter initiative to legalize recreational cannabis), the Denver District Attorney wrote a letter warning Californian voters that since the legalization of recreational marijuana crime surged in Denver and Colorado at large. Not everyone shares this concern. Among economists, Gary Becker was a strong advocate of the legalization of drugs in general (Becker and Murphy, 2013), and in particular of marijuana in the wake of the first wave of legalization of recreational cannabis in the US (Becker, 2014). Becker and Murphy (2013) claimed that the largest costs of a prohibitionist approach to buying and selling drugs in the US are "the costs of the crime associated with drug trafficking", predicting that legalizing this market would "reduce the role of criminals in producing and selling drugs [and] improve many inner-city neighborhoods": "Just as gangsters were largely driven out of the alcohol market after the end of prohibition, violent drug gangs would be driven out of a decriminalized drug market". That is, letting the drug market emerge from illegality would make illegal activities in this market not pay, thus greatly reducing fertile ground for crime, a central theme in Becker's economic approach to crime (Becker, 1968).

To date, there is limited causal evidence supporting either side of the debate. The present paper contributes to the academic and policy discussion on this issue by providing an empirical investigation of the crime effects of legalizing recreational cannabis. In order to provide credible evidence, we exploit a quasi-experiment generated by the timing of the legalization process in the states of Washington (WA, henceforth) and Oregon (OR, henceforth). These are neighboring (hence similar, in many respects) states where voters attempted the legalization of cannabis for recreational use at the same time, in November 2012. The proposal passed in WA but was rejected in OR by a relatively small margin. Two years later, in November 2014, a new but essentially identical ballot initiative was passed in OR, aligning the regulation of recreational marijuana to the one in force in WA. This "accidental" 2-year lag allows us to combine difference-in-differences (DID, henceforth) and spatial regression

\footnotetext{
${ }^{1}$ According to opinion polls, voters' support for recreational cannabis is widespread and increasing in the US: $61 \%$ think that marijuana should be legal, up from 40\% in 2011 and $27 \%$ in 1979 (De Pinto et al., 2017 ).
} 
discontinuity (SRD, henceforth) research designs at the county level to identify the causal impact of the policy at the WA-OR border. We find across different specifications that the legalization of recreational marijuana has not increased crime. On the contrary, it reduced rapes by between $15 \%$ and 30\% (between 2 and 4 occurrences per 100,000 inhabitants), and thefts by between $10 \%$ and $20 \%$ (between 60 and 100 per 100,000 inhabitants). These empirical results support Becker and Murphy's conjectures and stand in sharp contrast with the presumption that drugs cause crime, a major argument in support of a prohibitionist approach to substance use.

At the level of analysis pursued in this paper, we cannot pin down the mechanisms operating behind these effects. One possibility is the direct psychotropic effect of consuming marijuana, effectively a sedative drug. The possible substitution away from alcohol and other drugs which make consumers more aggressive than if consuming cannabis is another candidate mechanism. Some evidence supporting these two channels is provided by a complementary analysis of the effect of the policy on substance consumption. By using data from the National Survey on Drug Use and Health, we find that the legalization of recreational marijuana in WA induced an increase in the consumption of cannabis of about 2.5 percentage points (off a base level of about 10\%), a decrease in the consumption of other drugs of about 0.5 points (off a base level of about 4\%), and a decrease in the consumption of both ordinary alcohol and binge alcohol of about 2 points (off base levels of about $50 \%$ and $20 \%$, respectively). A third possibility is that the police reallocates effort away from retail marijuana dealing and towards other types of offenses. Finally, moving retail cannabis deals from degraded streets to safe, legal shops most likely played a role. ${ }^{2}$

Our findings enrich the empirical literature on the crime effects of legal cannabis, which is mostly based on the evaluation of medical marijuana laws (MML) in the US. According to a 2009 statement by the California Police Chiefs Association, "public officials and criminal justice organizations who oppose MML often cite the prospect of increased crime", but research yields mixed results. Some researchers find no significant relationship between MML and crime (Keppler and Freisthler, 2012; Braakman and Jones, 2014; Morris et al., 2014; Freisthler et al., 2016; Shepard and Blackley, 2016). Others show that MML are associated with fewer homicides (Ingino, 2016), less violent crime in general because of reduced activity by drug-trafficking organizations (Gavrilova et al., 2017), and less property crime (Huber III et al., 2016). Chu and Townsend (2017) show that although there are no significant effects at

\footnotetext{
${ }^{2}$ Anecdotal evidence is provided by this message posted on Twitter by the Portland Police on June 10, 2016: "If you are looking to buy marijuana, go to a legit business and avoid street dealers who might rob you".
} 
the national level, MML seem to reduce both violent and property crime within some states. In a different context, Adda et al. (2014) study an experiment that depenalized cannabis possession in a London borough, finding a reduction in crime induced by the reallocation of police effort towards nondrug offenses. Experimental designs like the latter are quite unique, which is why the estimation of a causal effect going from legalizing cannabis to crime rates remains an elusive question (Miron, 2004).

The present paper makes progress in this respect by engineering a quasi-experiment that is able to provide first-pass causal evidence on the relationship between large-scale legalization of recreational cannabis and crime rates. A few recent papers analyze the effects of both medical and recreational marijuana laws. Brinkman and Mok-Lamme (2017), using highly disaggregated data for the city of Denver and an identification based on demand-side shocks to the location of dispensaries within the city find that crime drops in neighborhoods with more dispensaries, the disruption of the illegal market being the most plausible explanation. Dills et al. (2017) use nationwide survey data collected among high school students between 1977 and 2015, thus covering all changes in US marijuana laws over the past 40 years, and they find no impact of liberalizing cannabis on youth drug use, alcohol consumption, or youth criminal behavior. Finally, two similarly recent papers analyze recreational marijuana laws with a focus on the cross-border spillovers from legal to illegal markets. Hansen et al. (2017) exploit, like we do, the WA-OR quasi-experiment, as well as data on legal marijuana transactions in WA, to estimate how demand changed on the WA side of the border when the cannabis market was legalized in OR. They find a sizable reduction in volume of $41 \%$, and evidence that this reflects a drop in cross-border diversion (OR residents traveling to purchase marijuana in WA and bringing it back in OR) rather than in cross-border consumption (OR residents traveling to consume marijuana in WA). Hao and Cowan (2017) study in a difference-in-differences setting the effect of the legalization of recreational cannabis in Colorado and WA on drug law enforcement in neighboring states where marijuana is illegal, finding a sharp increase in marijuana possession arrests in counties located right across the border in these states. These cross-border spillovers are important to interpret our estimates, which are produced by an identification right at the WA-OR border and which are gross of any form of noncompliance on the OR side. We will return to this point later on.

The remainder of the paper is organized as follows. Section 2 describes the quasiexperiment we analyze. The data are presented in Section 3 and the identification strategy in Section 4. Section 5 reports the results. Section 6 discusses mechanisms and concludes. The Appendix contains some robustness checks. 


\section{The quasi-experiment}

Possessing, using, selling, and cultivating marijuana is illegal under US federal law, except for restricted uses, since the Marihuana Tax Act of 1937. The Controlled Substance Act of 1970 classified marijuana and tetrahydrocannabinols among the drugs listed in Schedule I, which have high potential for abuse and no accepted medical value. State legislations have recently become more permissive. In 1996 California was the first state to legalize marijuana for medical purposes, followed by 28 additional states and DC over the following years. Over the last five years, marijuana consumption has also been allowed for recreational purposes: Colorado and WA in 2012, Alaska, OR, and DC in 2014, California, Nevada, Maine and Massachusetts in 2016, and Vermont in 2017.

This paper focuses on the legalization of recreational marijuana in WA and OR. At the general election ballot of November 2012, voters in WA approved with $55.7 \%$ of votes Initiative 502, which allows producing, processing, and selling cannabis, subject to licensing and regulation by the Liquor Control Board, allows limited possession by persons aged 21 and over (but not home cultivation), and taxes sales. Legal possession began on December 9, 2012. Regulations for producers, processors and sellers were approved in 2013 and retail sales of recreational cannabis began July 8, 2014. At the same general election ballot of November 2012, voters in OR rejected with a 53.4\% majority Measure 80, which would have allowed personal marijuana cultivation and use without license, and created a commission to regulate commercial marijuana cultivation and sale. Two years later, at the November 2014 general election ballot, voters in OR approved with $56.1 \%$ of votes Measure 91 , a cannabis law that is similar to the one passed in WA in 2012 in terms of taxing sales and subjecting them to regulation and licensing by the Liquor Control Commission, but more permissive in terms of possession and cultivation. ${ }^{3}$ Legalization of possession, use and home cultivation started in OR in July 2015, recreational sales through medical dispensaries in October 2015, and retail store licenses began in October 2016.

We claim that these events generate a quasi-experiment. The simultaneous attempt to legalize recreational marijuana at the end of 2012 in both WA and OR, the relatively small margin of rejection in OR in 2012, and the subsequent approval at the end of 2014 generate a 2-year lag during which cannabis was legal only on one side of the border of two similar states where voters had a similar attitude towards legal cannabis and a similar experience with MML. Specifically, in 2013 and 2014 recreational cannabis was legal in WA but not

\footnotetext{
${ }^{3}$ In OR, home cultivation of up to four plants per household is allowed. Adults over the age of 21 are allowed to carry 1 ounce and keep 8 ounces at home, whereas WA establishes a possession limit of 1 ounce.
} 
in OR, while in 2015 and subsequent years it was legal in both states. Figure 1 illustrates. Although retail sales of recreational cannabis was not possible in WA before July 2014, we argue that the relevant treatment is the legal status of marijuana, notably legal possession for nonmedical purposes, which began in WA in December 2012. This is the treatment that we study. We apply to this quasi-experiment a research design that combines a DID design (where WA acts as the treatment group, OR as the control group, 2010-2012 is the prelegalization period and 2013-2014 is the post-legalization period) and a SRD design (where the WA-OR border marks a discontinuity in the legal status of cannabis in 2013-2014). The combined design allows identifying the causal impact of legal cannabis on violent and property crime at the WA-OR border. ${ }^{4}$

Figure 1: Timeline of marijuana legal status in Washington (WA) and Oregon (OR)

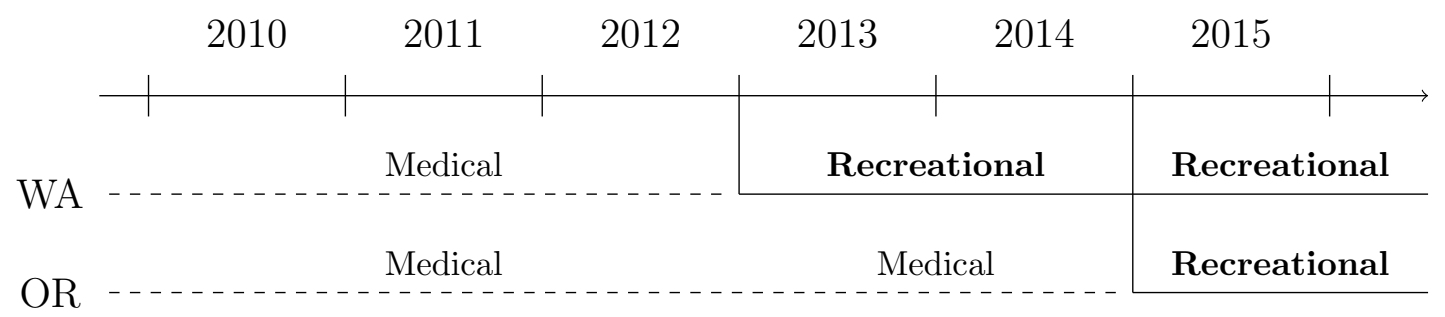

The potential confounding factor in our analysis is that other legal or institutional changes affecting crime rates in WA or OR may have taken place in 2013-2014. A search for such changes revealed no relevant events. In WA, a reorganization of the 911 emergency call system took place, and there were reforms related to health services, regulation of wine and beer, and drug courts. There were also changes in the statute of limitations for child molestation, incest (victim under age eighteen), and rape (victim under age eighteen), as well as new norms concerning commercial sale of sex and commercial sexual abuse, sexually violent predators, and sexual violence at school. However, all of these changes were too marginal to exert a plausible first-order effect on crime in the short run. As for OR, a reform of the sentencing and corrections system was passed in 2013. The reform aimed at reducing prison population and at redirecting savings towards front-line public safety programs. To the extent that such a reform reduced crime on the OR side of the border, our estimates of the differential effects of recreational marijuana in WA would be biased towards zero.

\footnotetext{
${ }^{4}$ Figure 1 also suggests that a quasi-experiment in reverse takes place in 2015 , with OR being treated in that year. We later include this experiment in the analysis as part of our checks on the baseline specification and results. Unfortunately, at the time this study was completed, county-level crime data for year 2016 had not been released yet.
} 


\section{Data}

The main data employed in our analysis are crime statistics at the county level from the US Uniform Crime Reporting (UCR) for years 2010 to 2014. The data base contains the number of offenses reported by the sheriff's office or county police department. For the reasons detailed below, these are not necessarily the county totals, but they are the only publicly available information from the UCR at the county level of disaggregation. For each reporting county and year, we have the total number of known offenses against persons or property, by type of offense. The final data set is an unbalanced panel (because not all counties report crime data every year) consisting of 335 observations for 75 counties, 36 in OR and 39 in WA. County-level population from the 2010 Census is used to obtain crime rates per 100,000 inhabitants. Latitude and longitude of each county's centroid as well as shortest distance of the centroid from the WA-OR border are computed using a GIS software. The distributions of crime counts during the pre (2010-2012) and post (2013-2014) periods of our analysis are reported in Figure 2, and the spatial distributions of the associated crime rates are reported in Figure 3. These distributions show two well known facts. First, the incidence of crime is higher in WA than in OR. Second, the distribution is shifting to the left between the two periods, i.e., crime is decreasing, in line with the national trend. Moreover, these facts hold around the WA-OR border as well as away from the border.

These patterns are displayed numerically in Table 1, which reports average crimes rates in WA and OR as resulting from aggregating the county-level rates via population-weighted averages. The top half of the table refers to all counties, while the bottom half restricts to counties at the WA-OR border (10 in OR and 11 in WA), which is where the crime effect is identified in our econometric analysis. Because these rates result from the aggregation of county-level reports in the UCR, they do not coincide with state-level rates. The reason of the discrepancy is twofold, as explained by the FBI's Criminal Justice Information Services Division at the UCR website. First, "only data for city law enforcement agencies 10,000 and over in population and county law enforcement agencies 25,000 and over in population are on this site". That is, crimes occurring in smaller cities are not counted for the published county-level totals. Second, "Because not all law enforcement agencies provide data for complete reporting periods, it is necessary to estimate for the missing data" when building statistics beyond the county level of aggregation. That is, the FBI imputes crime counts to nonreporting agencies when building estimates at the state and nation levels. 


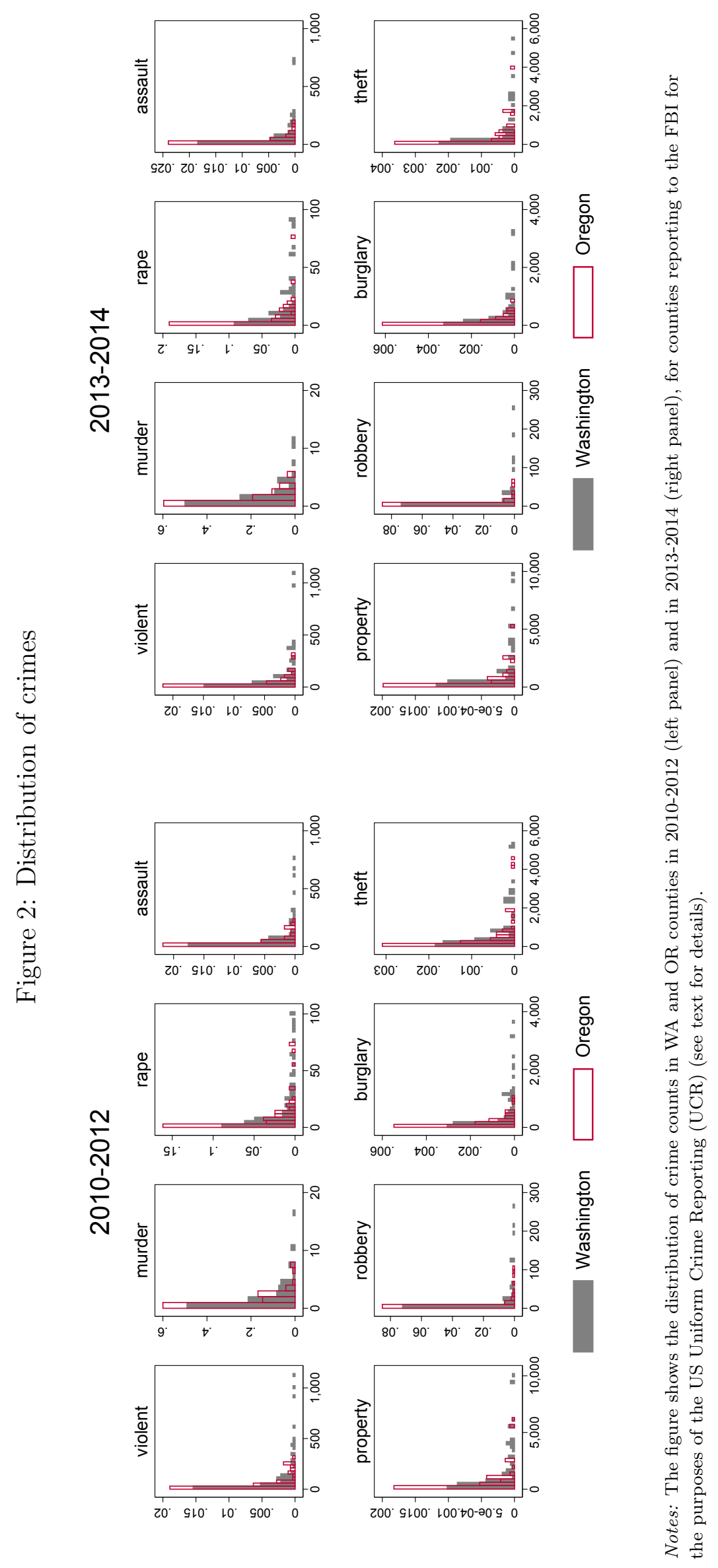


Figure 3: Spatial distribution of crime rates

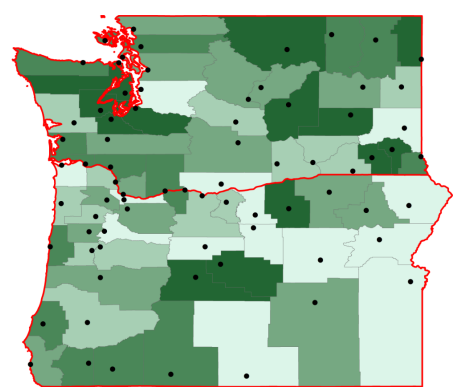

(a) violent, 2010-2012

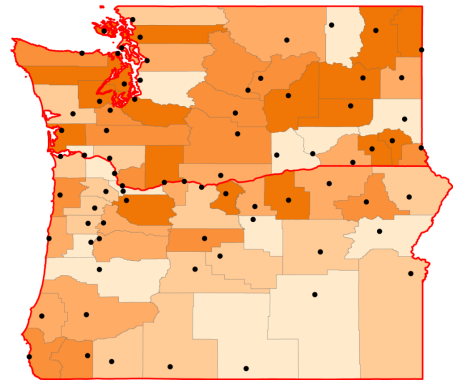

(c) property, 2010-2012

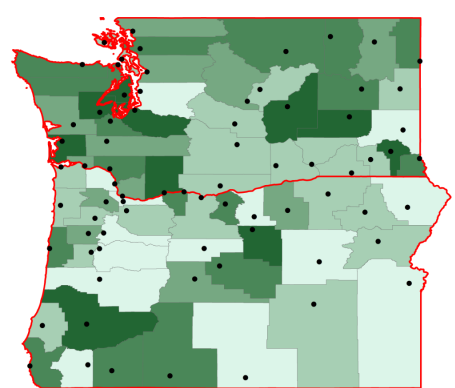

(b) violent, 2013-2014

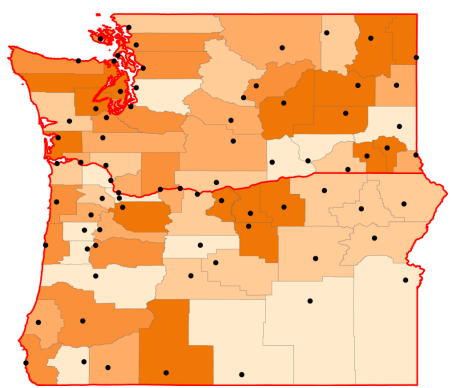

(d) property, 2013-2014

Notes: Spatial distribution of violent (top; legend: 0-25; 25-50; 50-75; 75-100; 100+) and property (bottom; legend: 0-400; 400-650; 650-900; 900-1200; 1200+) crime rates per 100,000 inhabitants in WA and OR counties in 2010-2012 (left) and in 2013-2014 (right). The border between WA (north) and OR (south) is the thick line.

Table 1: Aggregated county-level crime rates

\begin{tabular}{lcccccccc}
\hline & All violent & Murder & Rape & Assault & Robbery & All property & Burglary & Theft \\
\hline All WA: & & & & & & & & \\
$2010-2012$ & 65.27 & 0.88 & 9.96 & 43.54 & 10.88 & 791.86 & 272.59 & 444.77 \\
$2013-2014$ & 61.26 & 0.76 & 9.40 & 41.22 & 9.87 & 741.08 & 252.48 & 409.02 \\
All OR: & & & & & & & & \\
2010-2012 & 46.45 & 0.77 & 7.34 & 31.75 & 6.60 & 586.43 & 142.48 & 398.27 \\
$2013-2014$ & 39.80 & 0.75 & 6.48 & 26.64 & 5.20 & 551.83 & 127.42 & 378.39 \\
Border WA: & & & & & & & & \\
$2010-2012$ & 59.40 & 0.52 & 13.93 & 36.34 & 8.60 & 786.03 & 219.84 & 489.34 \\
$2013-2014$ & 57.74 & 0.65 & 10.40 & 40.13 & 6.56 & 655.57 & 197.58 & 382.51 \\
Border OR: & & & & & & & & \\
2010-2012 & 16.16 & 0.36 & 2.24 & 11.76 & 1.80 & 237.37 & 49.51 & 166.36 \\
$2013-2014$ & 16.69 & 0.11 & 1.36 & 13.21 & 2.01 & 192.24 & 40.98 & 136.53 \\
\hline
\end{tabular}

Notes: The table reports average crimes per 100,000 inhabitants in WA and OR as resulting from aggregating the county-level counts reported in the Uniform Crime Reporting Statistics. A county may report in one year but not in another one, so the underlying panel is unbalanced. The averages are weighted by county population. 
We also employ data from the National Survey on Drug Use and Health (NSDUH) to include in our analysis information on substance consumption. Specifically, we pulled from the NSDUH the consumption rates of marijuana, other federal illicit drugs, and alcohol, as well as the frequency of binge drinking. These statistics are publicly available only as averages over the 2010-2012 and 2012-2014 periods. Fortunately, these roughly correspond to the "pre" and "post" periods in our baseline DID-SRD model. Therefore, analysis of consumption data will effectively be over two periods only (vs. five years in the analysis of crime data). Table 2 reports these consumption rates. Information on consumption may shed some light on competing channels in the explanation of our results, and it allows us to also implement a tentative fuzzy DID-RD (where marijuana consumption is the regressor of interest and the legal status of recreational cannabis acts as an instrumental variable) as a robustness check on our baseline specification. Unfortunately, this can only be a check because the NSDUH data set available to us has severe limitations. In particular, in addition to the aggregation over years, for smaller counties the data come as aggregates for larger units consisting of groups of neighboring counties. In these cases, each county in the group is imputed the group-level average rate of consumption, and this is a very crude approximation. ${ }^{5}$

Table 2: Substance consumption rates at the county level

\begin{tabular}{lcccc}
\hline & Marijuana & Other drugs & Alcohol & Binge alcohol \\
\hline All WA: & & & & \\
$2010-2012$ & 0.102 & 0.044 & 0.560 & 0.222 \\
$2012-2014$ & 0.127 & 0.039 & 0.542 & 0.206 \\
All OR: & & & & \\
2010-2012 & 0.112 & 0.042 & 0.596 & 0.214 \\
2012-2014 & 0.122 & 0.040 & 0.579 & 0.213 \\
Border WA: & & & & \\
2010-2012 & 0.093 & 0.042 & 0.535 & 0.223 \\
2012-2014 & 0.101 & 0.034 & 0.486 & 0.199 \\
Border OR: & & & & \\
2010-2012 & 0.145 & 0.050 & 0.630 & 0.238 \\
2012-2014 & 0.130 & 0.043 & 0.600 & 0.233 \\
\hline
\end{tabular}

Notes: Average rates of substance use in WA and OR counties, estimated from the rates reported in the National Survey on Drug Use and Health. The averages are weighted by county population.

\footnotetext{
${ }^{5}$ For this reason, when employing consumption data in the regression analysis we do not cluster standard errors at the county level.
} 


\section{Econometrics}

Our research design combines a DID design with a SRD design at the WA-OR border. Such a combined design allows identifying the effect of the legalization policy at the WA-OR border, where treated and control counties offer a better comparison. Formally, let $c_{i t}$ be the crime rate in county $i$ and year $t$, and define the following binary variables: first, $w_{i}=1$ if county $i$ is located in WA (treatment), and $w_{i}=0$ if county $i$ is located in OR (control); second, $p_{t}=1$ if year $t>2012$ (post), and $p_{t}=0$ if year $t \leq 2012$ (pre). The DID-SRD design ("Difference-in-Spatial-Discontinuity", Dickert-Conlin and Elder, 2010; Gagliarducci and Nannicini, 2013) is implemented parametrically by the following linear model:

$$
c_{i t}=k+\alpha p_{t}+\beta w_{i} p_{t}+f\left(g e o_{i}\right) p_{t}+g\left(g e o_{i}\right) w_{i} p_{t}+\theta_{i}+\xi_{i t}
$$

where $k$ is a constant, $f($.$) and g($.$) are polynomials of the same order in the geographic$ location of county $i, \theta_{i}$ are county fixed effects, and $\xi_{i t}$ are residual determinants of crime. Coefficient $\beta$ is the SRD estimate of the change in crime rates in WA between the pre and post periods at the WA-OR border, i.e., by how much liberalizing recreational cannabis in WA changed the WA-OR crime gap at the border. As usual, conditioning on county fixed effects and time effects allows us to net out unobserved local characteristics affecting crime that do not change over time, as well as those crime-related factors that vary over time but are common to all counties. Moreover, by conditioning on the geographic location of the county and by allowing for different effects of such location before and after the legalization, this design controls for the effect of geographic location on crime rates, in addition to forcing identification at the border. The specification of polynomials $f\left(g e o_{i}\right)$ and $g\left(g_{e} o_{i}\right)$ is therefore a crucial step in our identification strategy. As for the functional form, we employ quadratic polynomials (Gelman and Imbens, 2017). As for $g o_{i}$, our baseline specification uses the minimum distance of the county centroid from the border. This is a one-dimensional index of location which offers the advantage of a straightforward graphical, nonparametric representation of the DID-SRD effect of the policy. However, it has the drawback of considering two counties whose centroids have similar latitude but possibly very different longitude as adjacent, when in fact they may be located at the opposite ends of the two states. We show in the Appendix that our results are robust to employing a two-dimensional polynomial in latitude and longitude (Dell, 2010). ${ }^{6}$

\footnotetext{
${ }^{6} \mathrm{~A}$ more sophisticated, fully nonparametric procedure that is able to recover parameter $\beta$ in Equation (1) at all border points is suggested by Keele and Titiunik (2015). Unfortunately this procedure is not feasible here, due to the aggregate nature of the data and consequent small sample size.
} 
Identification of model (1) requires a combination of the conditions ensuring identification in a DID and in a SRD model. That is, roughly speaking, parallel trends at the border and continuity at the border of difference-in-differences of pre-treatment variables. A convenient way of testing the parallel trend assumption in this context is to estimate model (1) using a full set of lags and leads of the treatment, i.e.,

$$
c_{i t}=k+\sum_{j=2011}^{2014} \alpha_{j} \mathbb{I}[t=j]+\sum_{j=2011}^{2014} \beta_{j} \mathbb{I}[t=j] w_{i}+f\left(g e o_{i}\right) p_{t}+g\left(g e o_{i}\right) w_{i} p_{t}+\theta_{i}+\xi_{i t}
$$

where $\mathbb{I}[$.$] is the indicator function, and year 2010$ is omitted to avoid collinearity. As shown below in Section 5, the hypotheses that $\beta_{2011}=0$ and $\beta_{2012}=0$ cannot be rejected for any crime category, which corroborates the parallel trend assumption in the DID-SRD model. As for the continuity of difference-in-differences of pre-treatment variables, given that demographic and socioeconomic variables are slow-moving in the context under investigation, the only threat to identification is the presence of concomitant (to the legalization of recreational cannabis in WA) legislation or other events that may have affected crime on either side of the WA-OR border. As discussed in Section 2, no relevant changes seem to have taken place in the period under investigation in either WA or OR. On the contrary, a relevant fact for the interpretation of our estimates is the cross-border spillover following the legalization of recreational cannabis in WA (Hansen et al., 2017; Hao and Cowan, 2017). Because these spillovers take the form of marijuana diversion from WA into OR and more intense police activity on the OR side of the border, our estimates should be interpreted as lower bounds of the effect of interest.

Finally, we will leverage the substance consumption data described in Section 3 in a twofold way. Consumption will be first used as an outcome in Equation 1. This can be interpreted as a "first stage", which we then use to estimate via 2SLS a tentative fuzzy DID-SRD where the treatment is marijuana consumption, a continuous treatment denoted by $m_{i t}$, and the outcome is crime. This model can be written as

$$
c_{i t}=k+\alpha p_{t}+\beta m_{i t}+f\left(g e o_{i}\right) p_{t}+g\left(g e o_{i}\right) w_{i} p_{t}+\theta_{i}+\xi_{i t},
$$

where the legalization of cannabis in WA, i.e., $w_{i} p_{t}$, acts as an instrument for $m_{i t}$. From this viewpoint, the baseline specification in Equation 1 yields the intention-to-treat effects (ITT) of the legalization policy. 


\section{Results}

Preliminary graphical evidence about the causal effect of legalizing recreational marijuana is given by Figure 4. The figure plots nonparametric estimates (from local linear regressions) of the difference between county-level crime rates before (2010-2012) and after (2013-2014) the WA legalization, as a function of the minimum distance (measured in hundreds of kilometers) of the county centroid from the WA-OR border. In each panel of Figure 4, the difference between the variations in crime rates at the border (i.e., the jump at zero distance) is a nonparametric estimate of the effect of legalizing cannabis. Except for murders (for which the variation is essentially zero on both sides of the border) and assaults, the drop in crime on the WA side of the border is much larger than the corresponding drop on the OR side. ${ }^{7}$

Figure 4: Variation in crime between before and after the WA legalization
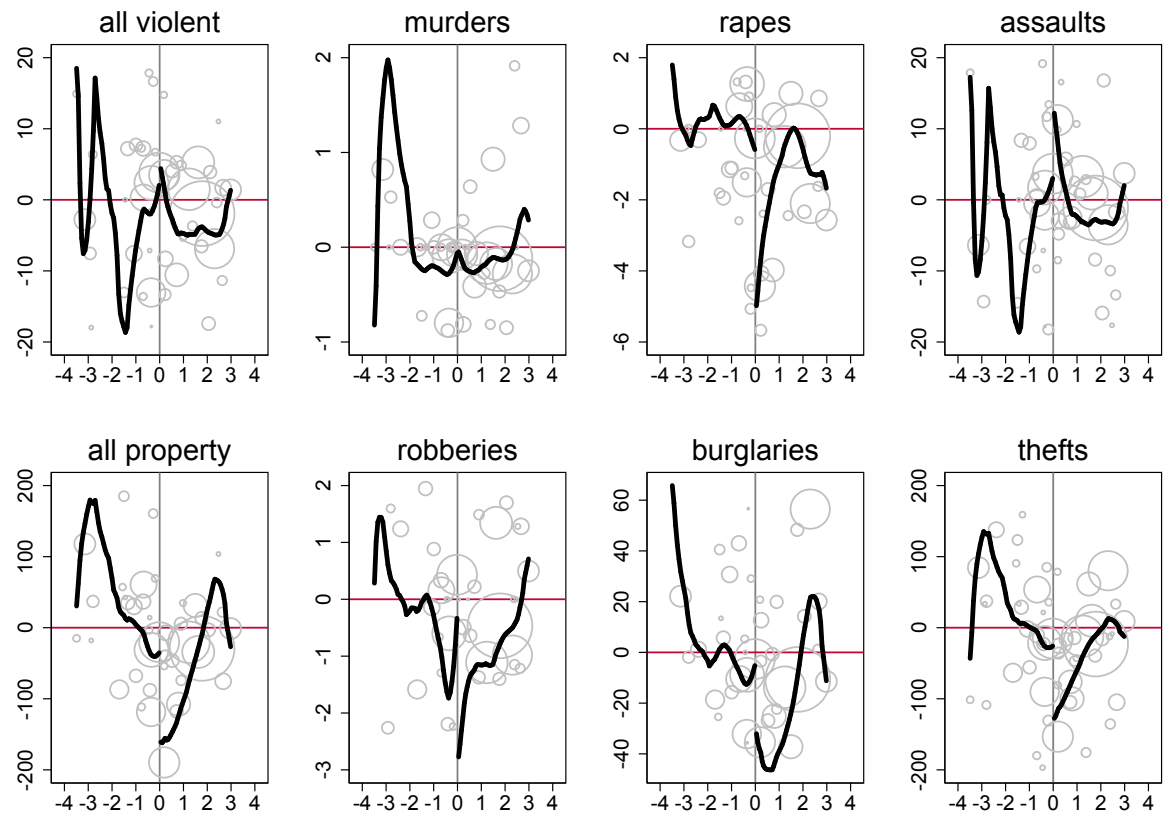

Notes: Variation in county-level crimes per 100k inhabitants (x-axis) as a function of the distance of the county centroid from the OR-WA border measured in hundreds Km (y-axis). Positive distance means that the county is located in WA, negative distance means that the county is located in OR. The jump at zero distance is a nonparametric DID-SRD estimate of the effect of the legalization policy on crime. The lines are smoothed county-level differences in crime rates obtained from local linear regressions, weighted by county population, employing a triangular kernel and a bandwidth of $100 \mathrm{Km}$. The circles represent the underlying raw crime rates (some off-scale points are omitted), and their size is proportional to county population in 2010.

\footnotetext{
${ }^{7}$ Note that for rapes, robberies, and property crimes there is a marked reversion towards zero while moving away from the border and into WA. Keeping in mind that the regression line is population-weighted, it is evident from the figure (specifically, from the circles) that this reversion is driven by a relatively very large county whose centroid is at about $200 \mathrm{~km}$ from the border. This turns out to be King county, where Seattle is located. A zero at that point means that there was no relevant variation in those particular crime categories in King county in 2013-2014 with respect to 2010-2012. However, this fact is mute, per se, in the absence of a counterfactual. Our research design generates a counterfactual at the WA-OR border only, not away from the border.
} 
Figure 5 illustrates the analogous evidence for consumption. The figure suggests that, following the legalization, bordering WA counties experienced an increase in marijuana consumption relative to their OR counterparts, and a decrease in the consumption of other drugs and binge alcohol.

Figure 5: Variation in consumption between before and after the WA legalization
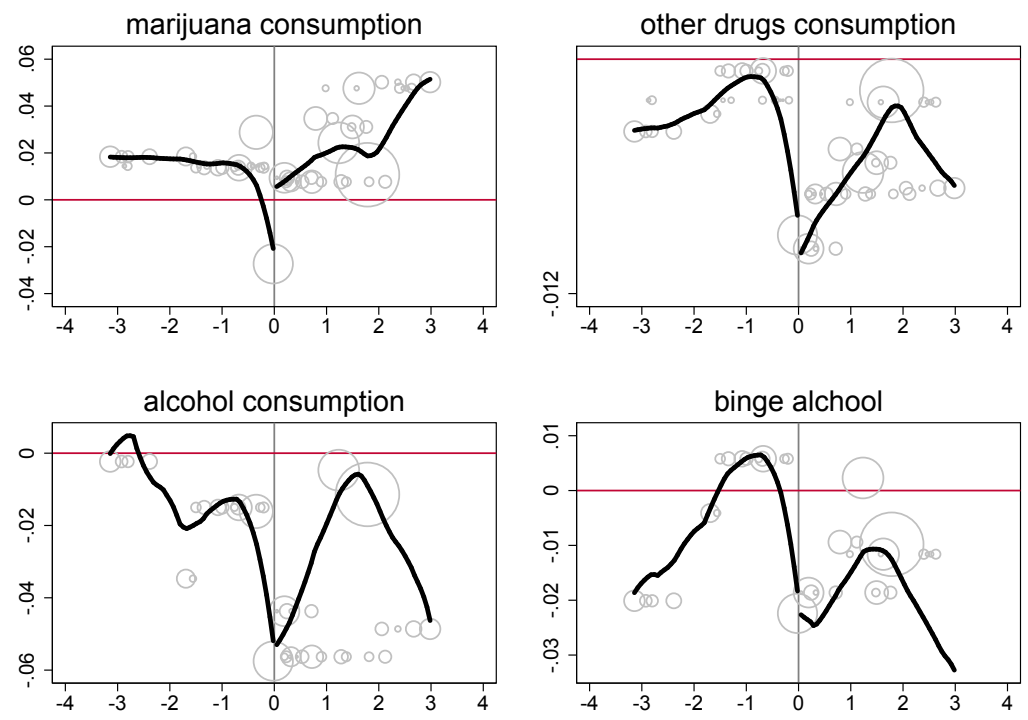

Notes: Variation in county-level rates of use of substances (x-axis) as a function of the distance of the county centroid from the OR-WA border measured in hundreds Km (y-axis). Positive distance means that the county is located in WA, negative distance means that the county is located in OR. The jump at zero distance is a nonparametric DID-SRD estimate of the effect of the legalization policy on consumption. The lines are smoothed county-level differences in crime rates obtained from local linear regressions, weighted by county population, employing a triangular kernel and a bandwidth of $100 \mathrm{Km}$. The circles represent the underlying raw crime rates (some off-scale points are omitted), and their size is proportional to county population in 2010.

A more formal analysis is provided in Table 3, which reports estimates from Equation (1) after specifying $f\left(g o_{i}\right)$ and $g\left(g e o_{i}\right)$ as second-order polynomials in shortest distance of the county centroid from the border. The point estimates for violent and property crimes are all negative. The one exception is murder, but the point estimate is small and statistically insignificant. The estimated drops for rapes and theft, instead, are statistically precise and sizable. For rapes, the reduction is 4.2 offenses per 100,000 inhabitants, which is about $30 \%$ of the 2010-2012 rate in border counties. For thefts, the reduction is 105.6 offenses per 100,000 inhabitants, which is about $20 \%$ of the 2010-2012 rate in border counties. Note that the parametric estimates of $\beta$ in Table 3 are in the same ballpark of the jump at zero-distance in Figure 4, except for burglaries, suggesting that our parametric choices in the baseline model are not driving the results. This evidence supports the conjecture that legalizing recreational cannabis does not increase crime, and possibly reduces it. 
Table 3: Effect of recreational cannabis on crime, baseline results

\begin{tabular}{ccccccccc}
\hline & violent & murder & rape & assault & robbery & property & burglary & theft \\
\hline$\hat{\beta}$ & -6.53 & 0.23 & $-4.21^{* *}$ & -1.30 & -1.26 & $-148.06^{* *}$ & -36.32 & $-105.62^{*}$ \\
& $(6.77)$ & $(0.40)$ & $(1.11)$ & $(7.74)$ & $(1.69)$ & $(44.91)$ & $(19.54)$ & $(35.39)$ \\
$N$ & 335 & 335 & 335 & 335 & 335 & 335 & 335 & 335 \\
\hline
\end{tabular}

Notes: The table reports estimates of $\beta$ from OLS on Equation 1, employing second-order polynomials in minimum distance of the county centroid from the border. The coefficient indicates by how much legalizing recreational cannabis in WA changed the difference in crime rates right across the WA-OR border. Robust standard errors clustered at the county level are reported in parentheses. Each county is weighted in the regression based on the size of its population in the 2010 Census. Significance level: ${ }^{*} 5 \%$; $* * 1 \%$ or better.

As explained in Section 3, the parallel trend assumption underlying our identification can be checked by estimating Equation (2) and by testing that $\hat{\beta}_{t}$ is zero for $t<2013$. Table 4 implements this procedure and provides evidence in favor of the parallel trend assumption. As the table shows, the estimated coefficients before the legalization of recreational marijuana in WA are all statistically indistinguishable from zero. Only the post-legalization coefficients are significant, and are in line with those reported in Table 3.

Table 4: Effect of recreational cannabis on crime, by year

\begin{tabular}{lcccccccc}
\hline & violent & murder & rape & assault & robbery & property & burglary & theft \\
\hline$\hat{\beta}_{2011}$ & -5.89 & 0.28 & -1.31 & -3.87 & -0.99 & 8.49 & 5.47 & 4.48 \\
& $(5.30)$ & $(0.26)$ & $(0.98)$ & $(4.43)$ & $(1.20)$ & $(31.45)$ & $(10.95)$ & $(21.25)$ \\
$\hat{\beta}_{2012}$ & -3.85 & 0.27 & -2.32 & 0.11 & -1.91 & -29.20 & 16.36 & -38.70 \\
& $(6.24)$ & $(0.34)$ & $(1.24)$ & $(5.02)$ & $(1.76)$ & $(38.32)$ & $(13.94)$ & $(27.60)$ \\
$\hat{\beta}_{2013}$ & -6.18 & 0.39 & $-5.45^{* *}$ & 1.02 & -2.14 & $-137.71^{*}$ & -26.29 & $-101.76^{*}$ \\
$\hat{\beta}_{2014}$ & $(7.90)$ & $(0.44)$ & $(1.49)$ & $(8.75)$ & $(2.39)$ & $(55.98)$ & $(24.77)$ & $(43.92)$ \\
& -12.90 & 0.44 & $-5.34^{* *}$ & -5.78 & -2.22 & $-173.27^{* *}$ & -32.87 & $-132.18^{* *}$ \\
$N$ & $(7.40)$ & $(0.46)$ & $(1.39)$ & $(8.49)$ & $(1.66)$ & $(52.23)$ & $(22.85)$ & $(41.49)$ \\
& 335 & 335 & 335 & 335 & 335 & 335 & 335 & 335 \\
\hline
\end{tabular}

Notes: The table reports estimates of $\beta$ from OLS on Equation 2, employing second-order polynomials in minimum distance of the county centroid from the border. The coefficient indicates by how much legalizing recreational cannabis in WA changed the difference in crime rates right across the WA-OR border. Robust standard errors clustered at the county level are reported in parentheses. Each county is weighted in the regression based on the size of its population in the 2010 Census. Significance level: ${ }^{*} 5 \%$; ${ }^{* *} 1 \%$ or better. 
Effectively, the combined DID-SRD design identifies the effect at the border using counties away from the border to improve the estimates. Therefore, a DID using the sample of border counties should by and large reproduce the baseline pattern. This would confirm that the modeling choices underlying the SRD part of the design are not driving the result. As shown in Table 5 this is indeed the case. As it turns out, the estimates are even more precise than those obtained under the baseline specification despite the smaller sample size, reflecting the fewer parameters to be estimated when removing the polynomials in distance.

Table 5: Effect of recreational cannabis on crime, DID on border counties

\begin{tabular}{ccccccccc}
\hline & violent & murder & rape & assault & robbery & property & burglary & theft \\
\hline$\hat{\beta}$ & -3.41 & 0.27 & $-2.88^{* *}$ & 1.45 & $-2.25^{*}$ & $-112.12^{*}$ & $-25.46^{*}$ & $-88.50^{*}$ \\
& $(4.31)$ & $(0.39)$ & $(0.92)$ & $(5.33)$ & $(0.83)$ & $(41.55)$ & $(10.44)$ & $(33.44)$ \\
$N$ & 95 & 95 & 95 & 95 & 95 & 95 & 95 & 95 \\
\hline
\end{tabular}

Notes: The table reports DID estimates of the effect of legalizing recreational cannabis in WA using OR as a control group. Only counties at the WA-OR border are used in this analysis. Robust standard errors clustered at the county level are reported in parentheses. Each county is weighted in the regression based on the size of its population in the 2010 Census. Significance level: * $5 \% ; * * 1 \%$ or better.

Finally, Table 6 reports estimates from Equation (1) when using substance consumption as an outcome. Our DID-SRD estimates reveal that the legalization increased consumption of cannabis by about 2.5 percentage points (off a base level of about 10\%), decreased consumption of other drugs by about 0.5 points (off a base level of about $4 \%$ ), and decreased consumption of both ordinary alcohol (in a marginally significant way) and binge alcohol of about 2 points (off base levels of about $50 \%$ and 20\%, respectively). These effects on consumption are consistent with two possible mechanisms underlying the reduction in crime estimated in this paper, namely the sedative effect of marijuana, and the substitution away from other drugs and alcohol, which make consumers more aggressive than if consuming cannabis. We expand on this point in the concluding section.

As pointed out in Section 4, the effect of the policy on marijuana consumption reported in the first column of Table 6 can be regarded as the first-stage of an alternative fuzzy DIDSRD specification in which the treatment is marijuana consumption, $m_{i t}$, and the outcome is crime, $c_{i t}$, as in Equation (3). This should be regarded as a tentative exercise because, as discussed in Section 3, the consumption data we can use has severe limitations, and so the results must be interpreted as a rough guide to what one should expect from an exercise 
conducted with better data. Because $m_{i t}$ is measured in the data as the rate of marijuana consumption, the estimated $\beta$ are the DID-SRD crime effect of one additional percentage point of population consuming cannabis. The first-stage in the first column of Table 6 has a F-stat of 7.46. Therefore, the instrument is definitely a weak one in this sample and estimates are bound to be imprecise. With this caveat in mind, second stage results are reported in Table 7, which again confirms the pattern of the baseline results. The order of magnitude is also similar, keeping in mind that the coefficients in this table must be multiplied by 2.5 (the first-stage coefficient) before comparing them with those reported in Table $3 .{ }^{8}$

Table 6: Effect of recreational cannabis on consumption

\begin{tabular}{ccccc}
\hline & Marijuana & Other drugs & Alcohol & Binge alcohol \\
\hline$\hat{\beta}$ & $0.025^{* *}$ & $-0.005^{* *}$ & -0.023 & $-0.020^{* *}$ \\
& $(0.009)$ & $(0.001)$ & $(0.014)$ & $(0.007)$ \\
$N$ & 135 & 135 & 135 & 135 \\
\hline
\end{tabular}

Notes: OLS on Equation 1, employing second-order polynomials in minimum distance of the county centroid from the border, when measures of consumption are used as an outcome. The coefficient indicates by how much legalizing recreational cannabis in WA changed the difference in substance consumption right across the WA-OR border. For the data availability reasons explained in the text, this analysis of consumption is over two periods only. Standard errors are reported in parentheses. Each county is weighted in the regression based on the size of its population in the 2010 Census. Significance level: ${ }^{*} 5 \%$; ${ }^{* *} 1 \%$ or better.

Table 7: Effect of marijuana consumption on crime, 2SLS estimates

\begin{tabular}{ccccccccc}
\hline & violent & murder & rape & assault & robbery & property & burglary & theft \\
\hline$\hat{\beta}$ & -5.79 & 0.11 & -1.00 & -4.55 & -0.35 & -62.15 & -22.29 & -35.43 \\
& $(3.93)$ & $(0.37)$ & $(1.39)$ & $(3.42)$ & $(0.85)$ & $(33.53)$ & $(13.66)$ & $(20.32)$ \\
\multirow{2}{*}{$N$} & 124 & 124 & 124 & 124 & 124 & 124 & 124 & 124 \\
\hline
\end{tabular}

Notes: The table reports estimates of $\beta$ from 2SLS on Equation 3, employing the legalization of cannabis in WA as an instrument and second-order polynomials in minimum distance of the county centroid from the border. The coefficient indicates by how much an additional percentage point of population consuming cannabis in WA changed the difference in crime rates right across the WA-OR border. For the data availability reasons explained in the text, this analysis employing consumption data is over two periods only. Standard errors are reported in parentheses. Each county is weighted in the regression based on the size of its population in the 2010 Census. Significance level: * $5 \%$; * $1 \%$ or better.

\footnotetext{
${ }^{8}$ The Appendix contains additional robustness checks on the baseline results of Table 3: estimating a two-dimensional DID-SRD model by employing a second-order polynomial in latitude and longitude of the county centroid; use of a logarithmic transformation for the dependent variable; analysis of a reverse quasiexperiment that took place in 2015; and placebo treatments.
} 


\section{Concluding remarks}

The concern that legalizing cannabis for recreational purposes may increase crime occupies a prominent position in the public debate about drugs. Our analysis suggests that such a concern is not justified. We reach conclusions in line with what Becker and Murphy (2013) expected when advocating the full decriminalization of the drugs market, namely a crime drop: rapes dropped in WA by, approximately, between $15 \%$ and 30\%, and property crimes fell by between $10 \%$ and $20 \%$, an effect entirely driven by reduced thefts, which decreased by between $13 \%$ and $22 \%$.

Why legalizing the production and sale of cannabis affected criminal behavior? The reduced-form analysis conducted in this paper is silent about the underlying mechanisms. Nonetheless, we would like to offer our thoughts on plausible candidate explanations. There are four main suspects. First, cannabis use determines a variety of psychoactive effects, the most commonly reported one being a state of relaxation and euphoria (Hall et al., 2001; Green et al., 2003). Thus, increased consumption of marijuana reduces the likelihood of engaging in violent activities. Second, this effect is reinforced if cannabis is a substitute for violence-inducing substances such as alcohol, cocaine and amphetamines. Studies generally find that marijuana and alcohol are substitutes (DiNardo and Lemieux, 2001; Crost and Guerrero, 2012; Anderson et al., 2014; Kelly and Rasul, 2014). ${ }^{9}$ Our own results show that the legalization of recreational marijuana increased its consumption while reducing the consumption of other substances, including alcohol. ${ }^{10}$ These two channels may explain, in particular, the estimated drop in rapes. Consistent with this possibility, recent research shows that men consuming cannabis are less likely to engage in sexual aggression against their partners than men consuming alcohol (Shorey et al., 2017). Moreover, as Anderson et al. (2014) point out, "there is evidence of a link between alcohol abuse and violent crime, including domestic violence [...]. If the legalization of recreational marijuana leads to reduced alcohol consumption, we expect violent crime to fall." (p. 228).

Third, the legalization of recreational marijuana may induce a reallocation of police efforts

\footnotetext{
${ }^{9}$ Others find that they are complements (Williams et al., 2004; Wen et al., 2015). According to Anderson et al. (2014) this estimated complementarity may be spurious. As observed in Sabia et al. (2017), who study the effects of MML on body weight and health, the substitutability/complementarity between alcohol and marijuana seems to be heterogeneous, depending on age.

${ }^{10}$ Basic economics rationalizes this evidence: the legalization induced a reduction in the quality-adjusted full relative price of cannabis because of a reduction of market price (Smart et al., 2017) as well as the legal and social consequences (stigma) of purchasing illegal substances on the demand side. If the law of demand applies, an increase in consumption follows (Becker and Murphy, 1988) at the extensive and intensive margin: the number of consumers may increase and existing ones may consume more. Moreover, the consumption of substitute substances declines.
} 
away from cannabis pushers and consumers and towards other types of offenses, a channel emphasized by Adda et al. (2014) in a study of the crime effects of depenalizing possession of small quantities of cannabis. Such reallocation of police effort may be reinforced by expectations, and therefore its effects on crime have arguably materialized before the actual opening of dispensaries and legal retail trade in WA following the 2012 vote. This would be consistent with detecting an impact on crime rates as soon as 2013-2014. This channel is consistent with a reduction of crime across the board.

Finally, the policy may have reduced the role for criminal gangs and small criminals in local cannabis markets (Becker and Murphy, 2013). The legalization of recreational cannabis leads to the emergence of a legal market, which offers more safety and more reliable product quality via legitimate business. This likely drives illegal sellers out of the market. The legalization thus reduces the involvement of small criminals as drug dealers and pushers, and so the risk of being victimized while buying or consuming. This mechanism fits recent empirical evidence that illegal markets are causally associated with crime (Chimeli and Soares, 2017) and it may explain both the drop in rapes and thefts that we find. To be clear, we don't know what previous dealers do after the legalization of the cannabis market, so this argument remains necessarily incomplete. ${ }^{11}$

Most likely, all of the channels we have discussed (and possibly other channels that we have not mentioned here) are at work behind our results and deserve a more thorough investigation in future research about the legalization of recreational cannabis. The ongoing legalization wave in the US will offer plenty of opportunities in this direction as more data become available. Our contribution is more modest and yet, we believe, important. By studying the WA-OR quasi-experiment and by providing first-pass evidence that legalizing cannabis may well cause a drop in crime we bring data to bear on the debate about the costs and benefits of a legal drugs market. An increase in crime does not appear to be a plausible cost.

\footnotetext{
${ }^{11}$ One might be concerned that even legal dispensaries attract criminals, e.g., to steal cash or marijuana. Yet, this concern is mitigated by the fact that dispensaries may take measures to reduce crime and increase guardianship, such as doormen or video cameras (Kepple and Freisthler, 2012).
} 


\section{References}

Adda, J., McConnell, B., and Rasul, I., 2014. Crime and the depenalization of cannabis possession: Evidence from a policing experiment. Journal of Political Economy, 122(5), $1130-1202$.

Anderson, D. M., and Rees, D. I., 2014. The legalization of recreational marijuana: How likely is the worst-case scenario? Journal of Policy Analysis and Management, 33(1), 221-232.

Becker, G. and Murphy, K., 1988. A theory of rational addiction. Journal of Political Economy, 96(4), pp.675-700.

Becker, G., and Murphy, K., 2013. Have we lost the war on drugs? The Wall Street Journal, January 4, 2013.

Becker, G., 1968. Crime and punishment: An economic approach. Journal of Political Economy, 76(2), 169-217.

Becker, G., 2014. Why marijuana should be decriminalized. The Becker-Posner Blog, February 23, 2014.

Braakman, N., and Jones, S., 2014. Cannabis depenalisation, drug consumption and crime: Evidence from the 2004 cannabis declassification in the UK. Social Science \& Medicine, 115, 29-37.

Brinkman, J., and Mok-Lamme D., 2017. Not in my backyard? Not so fast. The effect of marijuana legalization on neighborhood crime. Working paper, Federal Reserve Bank of Philadelphia.

Chimeli, A., and Soares R., 2017. The use of violence in illegal markets: evidence from mahogany trade in the Brazilian Amazon. American Economic Journal: Applied Economics, $9(4), 30-57$.

Chu, Y., and Townsend W., 2017. Joint culpability: The effects of medical marijuana laws on Crime. Mimeo.

Crost, B., and Guerrero, S., 2012. The effect of alcohol availability on marijuana use: Evidence from the minimum legal drinking age. Journal of Health Economics, 31(1), 112121.

De Pinto, J., Backus, F., Khanna, K., and Salvanto, A.(, 2017. Marijuana legalization support at all-time high. CBS NEWS April 20, 2017.

Dell, M., 2010. The persistent effect of Peru's mining Mita. Econometrica, 78(6), 1863-1910.

Dickert-Conlin, S., and Elder, T., 2010. Suburban legend: School cutoff dates and the timing of births. Economics of Education Review, 29, 826-841.

Dills, A., Goffard, S., and Miron, J., 2017. The effects of marijuana liberalizations: Evidence from monitoring the future. NBER Working Paper No. 23779. 
DiNardo, J., and Lemieux, T., 2001. Alcohol, marijuana, and American youth: the unintended consequences of government regulation. Journal of Health Economics, 20(6), 9911010 .

Freisthler, B., Ponicki, W. R., Gaidus, A., and Gruenewald, P. J., 2016. A micro-temporal geospatial analysis of medical marijuana dispensaries and crime in Long Beach, California. Addiction, 111(6), 1027-1035.

Gagliarducci, S., and Nannicini, T., 2013. Do better paid politicians perform better? Disentangling incentives from selection. Journal of the European Economic Association, 11(2), 369-398.

Gavrilova, E., Kamada, T., and Zoutman, F., 2017. Is legal pot crippling Mexican drug trafficking organizations? The effect of medical marijuana laws on US crime. The Economic Journal, forthcoming.

Gelman, A., and Imbens, G., 2017. Why high-order polynomials should not be used in regression discontinuity designs. Journal of Business \& Economic Statistics, forthcoming.

Green, B., Kavanagh, D., and Young, R., 2003. Being stoned: a review of self-reported cannabis effects. Drug and Alcohol Review, 22(4), 453-460.

Hall, W., Degenhardt, L., and Lynskey, M., 2001. The health and psychological effects of cannabis use. National Drug and Alcohol Research Centre, Monograph Series 44.

Hansen, B., Miller, K., and Weber, C., 2017. How extensive is inter-state diversion of recreational marijuana? NBER Working Paper No. 23762.

Hao, Z., Cowan, B., 2017. The cross-border spillover effects of recreational marijuana legalization. NBER Working Paper No. 23426.

Huber III, A., Newman, R., and LaFave, D., 2016. Cannabis control and crime: medicinal use, depenalization and the war on drugs. B.E. Journal of Economic Analysis \& Policy, 16(4.

Ingino, F., 2016. The heterogeneous effect of medical marijuana laws. Mimeo, University of Salerno.

Keele, L., and Titiunik, R., 2015. Geographic boundaries as regression discontinuities. Political Analysis, 23(1), 127-155.

Kelly, E., and Rasul, I., 2014. Policing cannabis and drug related hospital admissions: Evidence from administrative records. Journal of Public Economics, 112, 89-114.

Keppler, N. J., and Freisthler, B., 2012. Exploring the ecological association between crime and medical marijuana dispensaries. Journal of Studies on Alcohol and Drugs, 73(4), 523530 .

Miron, J. A., 2004. Drug war crimes: The consequences of prohibition. Oakland, CA: The Independent Institute.

Morris, R. G., TenEyck, M., Barnes, J. C., and Kovandzic, T. V, 2014. The effect of medical 
marijuana laws on crime: evidence from state panel data 1990-2006. PloS One, 9(3), e92816.

Sabia, J. J., Swigert, J., and Young, T., 2017. The effect of medical marijuana laws on body weight. Health Economics, 26(1), 6-34.

Shepard, E. M., and Blackley, P. R., 2016. Medical marijuana and crime: Further evidence from the western states. Journal of Drug Issues, 46(2), 122-134.

Shorey, R., Stuart, G., Moore, T., and McNulty, J., 2014. The temporal relationship between alcohol, marijuana, angry affect, and dating violence perpetration: A daily diary study with female college students. Psychology of Addictive Behaviors, 28(2), 516-523.

Smart, R., Caulkins, J., Kilmer, B., Davenport, S., and Midgette, G., 2017. Variation in cannabis potency and prices in a newly legal market: evidence from 30 million cannabis sales in Washington state. Addiction, forthcoming.

Wen, H., Hockenberry, J. M., and Cummings, J. R., 2015. The effect of medical marijuana laws on adolescent and adult use of marijuana, alcohol, and other substances. Journal of Health Economics, 42, 64-80.

Williams, J., Pacula, R. L., Chaloupka, F. J., and Wechsler, H., 2004. Alcohol and marijuana use among college students: economic complements or substitutes? Health Economics, 13(9), $825-843$. 


\section{Appendix: robustness checks}

This Appendix provides some specification and robustness checks on the main results. The first check consists of estimating a two-dimensional DID-SRD model by employing a second-order polynomial in latitude and longitude of the county centroid rather than a one-dimensional model based on minimum distance of the county centroid from the border as a running variable as in the baseline specification that produces Table 3. Such a twodimensional specification is similar to the one employed by Dell (2010). Results are reported in Table A1. Although estimates are more imprecise, the baseline pattern is confirmed.

Table A1: Effect of recreational cannabis on crime, polynomial in latitude and longitude

\begin{tabular}{ccccccccc}
\hline & violent & murder & rape & assault & robbery & property & burglary & theft \\
\hline$\hat{\beta}$ & -2.27 & 0.13 & -2.25 & 0.95 & -1.10 & $-97.40^{*}$ & -30.21 & $-62.30^{*}$ \\
& $(6.18)$ & $(0.46)$ & $(1.64)$ & $(5.66)$ & $(1.15)$ & $(42.23)$ & $(17.11)$ & $(28.79)$ \\
$N$ & 335 & 335 & 335 & 335 & 335 & 335 & 335 & 335 \\
\hline
\end{tabular}

Notes: The table reports estimates of $\beta$ from OLS on Equation 1, employing a second-order polynomial in latitude and longitude of the county centroid. The coefficient indicates by how much legalizing recreational cannabis in WA changed the difference in crime rates right across the WA-OR border. Robust standard errors clustered at the county level are reported in parentheses. Each county is weighted in the regression based on the size of its population in the 2010 Census. Significance level: ${ }^{*} 5 \%$; ${ }^{*} 1 \%$ or better.

Our results are also robust to employing a logarithmic transformation of the dependent variable (i.e., the log of the crime count as the left-hand side variable). Such a transformation accounts for possible nonlinearities in the relation between crime rates on the one hand and the explanatory and conditioning variables on the other. Table A2 reports the results. Despite the loss of sample size (due to the log scale, counties are dropped in years with zero occurrences) the conclusion is unchanged: legalizing recreational cannabis does not increase crime, and possibly reduces it. 
Table A2: Effect of recreational cannabis on crime, logarithmic scale for crime counts

\begin{tabular}{ccccccccc}
\hline & violent & murder & rape & assault & robbery & property & burglary & theft \\
\hline$\hat{\beta}$ & $-0.39^{* *}$ & 0.20 & $-0.33^{*}$ & -0.33 & $-0.75^{* *}$ & -0.06 & 0.04 & -0.11 \\
& $(0.14)$ & $(0.56)$ & $(0.16)$ & $(0.21)$ & $(0.19)$ & $(0.06)$ & $(0.06)$ & $(0.07)$ \\
$N$ & 221 & 135 & 221 & 221 & 221 & 221 & 221 & 221 \\
\hline
\end{tabular}

Notes: The table reports estimates of $\beta$ from OLS on Equation 1 when the dependent variable is the logarithm of the crime count, employing second-order polynomials in minimum distance of the county centroid from the border. The coefficient indicates by how much legalizing recreational cannabis in WA changed the difference in crime rates right across the WA-OR border in percentage terms, approximately. Robust standard errors clustered at the county level are reported in parentheses. Each county is weighted in the regression based on the size of its population in the 2010 Census. Significance level: ${ }^{*} 5 \% ; * * 1 \%$ or better.

An additional check of interest is based on exploiting the reverse quasi-experiment that took place in 2015. As illustrated in Section 2 of the paper, at the end of 2014 marijuana became legal also on the OR side of the border. Therefore, in 2015 the legal status of cannabis was identical in OR and WA, exactly like before 2013. Based on the results reported in the main text, we expect crime to drop in OR relative to WA in 2015. After augmenting the data set with 2015 crime data, we can include this reverse experiment in our analysis in two alternative ways. First, the analysis is repeated treating year 2015 as part of the "pre" period -where "pre" now means identical legal status of marijuana (see Figure 1 in the main text)- and re-estimating Equation 1 on the resulting sample. Here we expect the results to be unaffected because the treatment is still a different legal status of cannabis across the border, as in the baseline specification. The results reported in Table A3 confirm this expectation. Second, we analyze the plain reverse experiment. That is, we define years 2013-2014 as the pre-treatment period, year 2015 as post-treatment, and we consider OR as treated in 2015. In this case we expect again negative coefficients, i.e., a relative drop in crime on the OR side of the border. Estimating Equation 1 after re-defining this way time and treatment status yields the results reported in Table A4. The point estimates for rapes and thefts (although with large standard errors) are negative as expected, and their magnitude is in line with the effect observed in Table A3. This suggests that after the legalization in OR, the WA-OR crime gap is reverting to the level observed before the cannabis policies in WA and OR had diverged in 2013-2014. 
Table A3: Effect of recreational cannabis on crime: year 2015 as part of pre-treatment.

\begin{tabular}{ccccccccc}
\hline & violent & murder & rape & assault & robbery & property & burglary & theft \\
\hline$\hat{\beta}$ & -6.74 & 0.17 & $-4.39^{* *}$ & -1.92 & -0.61 & $-83.70^{*}$ & -12.58 & $-64.19^{*}$ \\
& $(4.99)$ & $(0.41)$ & $(1.57)$ & $(5.89)$ & $(1.52)$ & $(39.49)$ & $(15.21)$ & $(30.71)$ \\
$N$ & 398 & 398 & 398 & 398 & 398 & 398 & 398 & 398 \\
\hline
\end{tabular}

Notes: The table reports estimates of $\beta$ from OLS on Equation 1, employing second-order polynomials in minimum distance of the county centroid from the border. The coefficient indicates by how much legalizing recreational cannabis in WA changed the difference in crime rates right across the WA-OR border. The pre period now includes year 2015, when the legal status of cannabis was again identical across the border. Robust standard errors clustered at the county level are reported in parentheses. Each county is weighted in the regression based on the size of its population in the 2010 Census. Significance level: * $5 \%$; ** $1 \%$ or better.

Table A4: Effect of recreational cannabis on crime: year 2015 as reverse experiment

\begin{tabular}{ccccccccc}
\hline & violent & murder & rape & assault & robbery & property & burglary & theft \\
\hline$\hat{\beta}$ & 5.43 & -0.38 & -3.79 & 9.52 & 0.08 & -15.89 & 46.09 & -50.59 \\
& $(9.76)$ & $(1.25)$ & $(4.85)$ & $(7.86)$ & $(1.88)$ & $(84.08)$ & $(30.42)$ & $(55.60)$ \\
$N$ & 195 & 195 & 195 & 195 & 195 & 195 & 195 & 195 \\
\hline
\end{tabular}

Notes: The table reports estimates of $\beta$ from OLS on Equation 1, employing second-order polynomials in minimum distance of the county centroid from the border. The coefficient represents the difference in the spatial regression discontinuity estimates between the pre (2013-2014) and post (2015) periods, i.e., by how much legalizing recreational cannabis in OR changed the difference in crime rates right across the WA-OR border in 2015. Robust standard errors clustered at the county level are reported in parentheses. Each county is weighted in the regression based on the size of its population in the 2010 Census. Significance level: * $5 \%$;** $1 \%$ or better.

Finally, we report in Table A5 results from a placebo treatment. This consists of removing from the data the two years when the cannabis policy differed between WA and OR (i.e., years 2013 and 2014, see Figure 1 in the main text), and then defining years 2010-2012 as the pre-treatment period and year 2015 as the post-treatment period in the otherwise unchanged DID-SRD framework used so far. Because there is no policy difference between WA and OR in the pre and post periods so defined, no effect is expected. As the table shows, this is what we find. The placebo treatment has zero effect on rapes, and the estimates for property crimes become extremely noisy despite retaining a relatively large sample size. This suggests that all of the action behind the significant drop in crime reported in the main text comes from the two years when recreational marijuana is legal in WA but not in OR. 
Table A5: Effect of a placebo treatment

\begin{tabular}{ccccccccc}
\hline & violent & murder & rape & assault & robbery & property & burglary & theft \\
\hline$\hat{\beta}$ & -23.21 & 1.05 & 0.17 & -22.58 & -1.85 & -133.10 & -57.63 & -66.43 \\
& $(24.11)$ & $(1.15)$ & $(4.51)$ & $(20.48)$ & $(2.88)$ & $(157.84)$ & $(55.09)$ & $(104.90)$ \\
\multirow{2}{*}{$N$} & 266 & 266 & 266 & 266 & 266 & 266 & 266 & 266 \\
\hline
\end{tabular}

Notes: The table reports estimates of $\beta$ from OLS on Equation 1, employing second-order polynomials in minimum distance of the county centroid from the border. The treatment is a placebo, pretending cannabis was legalized at the end of 2010 and taking 2011 and 2015 as the post-legalization period. Robust standard errors clustered at the county level are reported in parentheses. Each county is weighted in the regression based on the size of its population in the 2010 Census. Significance level: ${ }^{*} 5 \%$; ${ }^{*} 1 \%$ or better. 